УДК 616.89-008.481:614.283:178.8:303.725.23

Для цитирования: Афанасьева Н.А., Березовская М.А., Коробицина Т.В., Пичугина Ю.А., Арапиев Ю.А., Виноградов К.А., Быкова В.В., Катаева А.В. Опыт применения метода математического моделирования психотических расстройств при сочетанном употреблении современных синтетических психоактивных веществ. Сибирский вестник психиатрии и наркологии. 2018; 4 (101): 28-34. https://doi.org/10.26617/1810-3111-2018-4(101)-28-34

\title{
Опыт применения метода математического моделирования психотических расстройств при сочетанном употреблении современных синтетических психоактивных веществ
}

\author{
Афранасьева Н.А. ${ }^{1}$, Березовская М.А. ${ }^{1}$, Коробицина Т.В. ${ }^{1,2}$, Пичугина Ю.А. ${ }^{1}$, \\ Арапиев Ю.А. ${ }^{1}$, Виноградов К.А. ${ }^{1}$, Быкова В.В. ${ }^{2}$, Катаева А.В. ${ }^{2}$ \\ ${ }^{1}$ Красноярский государственный медицинский университет им. профессора В.Ф. Войно-Ясенецкого \\ Россия, 660022, Красноярск, ул. Партизана Железняка, д. 1 \\ ${ }^{2}$ Сибирский федеральный университет \\ Россия, 660041, Красноярск, пр. Свободный, 79
}

\section{PEЗЮME}

Представлен анализ возможности создания математической компьютерной модели для диагностики психотических расстройств, вызванных употреблением современных синтетических психоактивных веществ. Несмотря на схожесть клинической картины психотических расстройств, вызванных приемом современных синтетических психостимуляторов и каннабиноидов, возможно выявление дифференциально-диагностических критериев психозов, причинно-следственных связей, имеющих большую значимость в терапии нарушений, вызванных употреблением синтетических психоактивных веществ.

Ключевые слова: математическое моделирование, ассоциативные правила, психоактивные вещества, шизофреноподобные психические расстройства.

\section{ВВЕДЕНИЕ}

Современная ситуация, связанная с употреблением различных психоактивных веществ как в России $[2,12]$, так и за рубежом, обостренно складывающаяся в последние несколько лет, характеризуется появлением на наркорынке и достаточно стремительным распространением новых синтетических психоактивных веществ со своеобразными клиническими эффектами $[11,16,19,20,21,22]$. Несмотря на разнообразие химического состава, обилие названий и способов применения, их объединяют выраженный психостимулирующий эффект и способность вызвать шизофреноподобные психотические расстройства $[1,7,10,14]$. Клинические проявления расстройств, вызванных употреблением синтетических психоактивных веществ, в подавляющем большинстве случаев представлены психомоторным возбуждением, двигательным беспокойством и шизофреноподобной симптоматикой. На фоне страха, тревоги, напряжения развиваются бред преследования, чувство опасности, галлюцинаторное ощущение слежки. Пациенты жалуются на ощущение воздействия на них с помощью встроенных микрочипов, специальной аппаратуры, сообщают о попытках со стороны правоохранительных органов «подбросить» им наркотики, тем самым «осуществить подставу». В ряде случаев пациенты испытывают слуховые галлюцинации обвиняющего и угрожающего характера $[3,4,9,15]$. При этом в литературе отсутствуют данные о признаках, позволяющих с высокой долей вероятности определить по особенностям клинической картины этиологию психоза.
В последнее время в медицине широко используются различные экспериментальные методы моделирования, в том числе биомедицинского моделирования закономерностей течения физиологических и патологических процессов в организме человека, что позволяет уточнить механизмы их системной организации [8]. Исследования, связанные с применением методов математического моделирования в медицине в условиях современной науки, достаточно быстро развиваются в нашей стране и за рубежом, являются одними из важных и значимых способов изучения закономерностей, лежащих в основе функционирования сложных систем. Математические компьютерные модели позволяют получить новые знания об изучаемых процессах путем проведения вычислительных экспериментов на компьютере и при этом избежать дорогостоящих опытов на животных $[6,13]$. Таковыми являются математическая теория кровообращения и опыт применения математического моделирования в клинической практике при интенсивной терапии, методы математического моделирования для изучения механизмов электромеханического сопряжения в ердце и др. В настоящее время исследователи ведут активный поиск математической модели диагностики заболеваний, а также патологических состояний [5] в различных областях медицины.

\section{ЦЕЛЬ ИССЛЕДОВАНИЯ}

Проанализировать возможность создания математической компьютерной модели для диагностики психотических расстройств, вызванных употреблением современных синтетических психоактивных веществ. 


\section{МАТЕРИАЛ И МЕТОДЫ}

Исследование проводилось на базе стационара ККБУЗ «Красноярский краевой наркологический диспансер № 1». Изучены истории болезни пациентов (222 мужчин), средний возраст которых $32,6 \pm 7,4$ года), перенесших психотические расстройства на фоне употребления новых синтетических ПАВ. Из исследования исключались больные с алкогольными психозами и синдромом отмены алкоголя. В анамнезе 100 человек ранее употребляли героин. Основной метод исследования - катамнестический. Были проанализированы истории болезни пациентов с возможностью проверить вероятную зависимость между принимаемыми препаратами, вероятную зависимость между наблюдаемыми симптомами, вероятную зависимость между употребляемыми синтетическими ПАВ и наблюдаемыми симптомами.

Обработка полученных данных проводилась при помощи программы математического компьютерного моделирования создания ассоциативных правил, которые позволяют находить закономерности между связанными событиями. Ассоциативное правило имеет вид: «Из события А следует событие В с некоторой вероятностью». При помощи использования алгоритмов поиска ассоциативных правил можно получить все возможные правила вида «Из А следует В» с различными значениями поддержки и достоверности. Количество правил ограничивается заранее установленными минимальными и максимальными значениями поддержки и достоверности, интервалом, который, с одной стороны, обеспечит нахождение неочевидных правил, а с другой их обоснованность $[17,18]$, что позволяет оценить значимость и достоверность выявленных причинноследственных связей.

\section{РЕЗУЛЬТАТЫ И ОБСУЖДЕНИЕ}

Проведенный анализ историй болезни пациентов, отобранных сплошным методом, показал, что в клинической картине психозов преобладали (в порядке убывания количественных значений представленности у больных): эмоциональное и двигательное возбуждение $(62,2 \%)$, бред преследования $(37,8 \%)$, зрительные и слуховые обманы восприятия $(30,2 \%)$, страх $(27,5 \%)$, ощущение угрозы жизни $(18,5 \%)$, тревога $(13,9 \%)$, ответы не по сути заданных вопросов $(8,1 \%)$. Исходя из результатов химико-токсикологического исследования (ХТИ), моноупотребление встречалось достоверно чаще, чем сочетанное употребление производных пировалерона с синтетическими каннабиноидами, производных пировалерона, синтетических каннабиноидов и других веществ $(66,7 \%$ и $33,3 \%$; $\mathrm{p}<0,05)$. При ХТИ методами лабораторной диагностики чаще всего выявлялись: метилендиоксипировалерон (МДПВ - 26,1\%) либо сочетание нескольких употребленных веществ $(34,7 \%)$, изолированное потребление синтетических каннабиноидов встречалось достоверно реже $(5,4 \% ; \mathrm{p}<0,05)$. При моноэтиологическом психозе (вызванном приемом одного синтетического психоактивного вещества), как на фоне употребления производных пировалерона, так и каннабиноидов, психотические нарушения достаточно вариабельны. В клинической картине у больных наблюдались бред преследования, страх, тревога, двигательное возбуждение, нарушения ориентировки в окружающем, бессвязная речь, уверенность в угрозе жизни, зрительные и слуховые галлюцинации. По клиническим признакам достоверно разграничить расстройства, обусловленные приемом синтетических каннабиноидов или производных пировалерона, трудно.

C помощью математического компьютерного моделирования полученные ассоциативные правила достоверно показали, какие симптомы чаще всего наблюдаются совместно при приеме синтетических психоактивных веществ (табл. 1), а также какие психоактивные вещества вызывают симптомы, указанные в качестве «причины» ассоциативного правила (табл. 2).

Зависимости между принимаемыми психоактивными веществами и наблюдаемыми симптомами

Т а б ли ц а 1

\begin{tabular}{|l|l|c|c|}
\hline \multicolumn{1}{|c|}{ Причина } & \multicolumn{1}{|c|}{ Следствие } & Поддержка, \% & Достоверность, \% \\
\hline Пол мужской, кодеин & Возбуждение & 2,3 & 100 \\
\hline Пол женский, галоперидол & Возбуждение & 2,3 & 100 \\
\hline Пол мужской, метилендиоксипировалерон, тропикамид & Бред преследования & 2,3 & 100 \\
\hline Пол мужской, метилендиоксипировалерон, пировалерон, тропикамид & Бред преследования & 2,3 & 100 \\
\hline Галоперидол & Возбуждение & 2,7 & 85,7 \\
\hline Пол мужской, пировалерон, тропикамид & Бред преследования & 2,7 & 85,7 \\
\hline Метилендиоксипировалерон, тропикамид & Бред преследования & 2,3 & 83,3 \\
\hline Метилендиоксипировалерон, галоперидол & Возбуждение & 2,3 & 83,3 \\
\hline Пировалерон, галоперидол & Возбуждение & 2,3 & 83,3 \\
\hline Метилендиоксипировалерон, пировалерон, тропикамид & Бред преследования & 2,3 & 83,3 \\
\hline Метилендиоксипировалерон, пировалерон, галоперидол & 2,3 & 83,3 \\
\hline Пировалерон, тропикамид & Возбуждение & 3,2 & 77,8 \\
\hline Пол мужской, тропикамид & Бред преследования & 2,7 & 75 \\
\hline Пол мужской, тропикамид & Бред преследования & 2,3 & 75 \\
\hline Пол мужской, декстрометорфан & Возбуждение & 2,7 & 71,4 \\
\hline Этанол, метилендиоксипировалерон & Возбуждение & 71,4 \\
\hline Этанол, пировалерон & Страх & 2,3 & 71,4 \\
\hline ПВП, тропикамид & Страх & 2,3 & 71,4 \\
\hline ПВП, тропикамид & Бред преследования & 2,3 & 71,4 \\
\hline
\end{tabular}


Анализируя данные таблицы 1, которые отражают симптомы («следствия»), чаще всего наблюдающиеся совместно при приеме психоактивных веществ, определяющих «причину» ассоциативных правил (выбраны 19 первых ранговых значений в порядке убывания достоверности и поддержки), можно отметить, что полученные ассоциативные правила (АП) в целом отвечают реальной действительности и могут быть использованы для прогно- зирования возможных симптомов у пациента, если известно, что ими были приняты психоактивные вещества, обозначенные как «причина» АП.

Обращает внимание, что в качестве «причины» АП с высоким уровнем достоверности часто фигурирует связь употребленного вещества с мужским полом (женский пол отмечен достоверно однократно только в «причине» с употреблением галоперидола).

Т а б ли ц а 2

Зависимости между симптомами и принимаемыми психоактивными веществами

\begin{tabular}{|c|c|c|c|}
\hline Причина & Следствие & \begin{tabular}{|c|} 
Поддержка, \\
$\%$
\end{tabular} & $\begin{array}{l}\text { Достовер- } \\
\text { ность, \% }\end{array}$ \\
\hline Суицидальные мысли & Пировалерон & 4,0 & 100 \\
\hline Желание спрыгнуть с высоты & Пировалерон & 3,6 & 100 \\
\hline Бред преследования, возбуждение, защита от преследователей (прячется) & МДПВ & 2,7 & 100 \\
\hline Бред преследования, возбуждение, защита от преследователей (прячется) & Пировалерон & 2,7 & 100 \\
\hline Бред преследования, возбуждение, защита от преследователей (прячется) & Пол мужской, МДПВ & 2,7 & 100 \\
\hline Бред преследования, возбуждение, защита от преследователей (прячется) & Пол мужской, пировалерон & 2,7 & 100 \\
\hline Бред преследования, возбуждение, защита от преследователей (прячется) & МДПВ, пировалерон & 2,7 & 100 \\
\hline Бред преследования, возбуждение, защита от преследователей (прячется) & $\begin{array}{l}\text { Пол мужской, МДПВ, } \\
\text { пировалерон }\end{array}$ & 2,7 & 100 \\
\hline Сенестопатия - вынимают или выпадают внутренности & Пировалерон & 2,3 & 100 \\
\hline Бред преследования, возбуждение, галлюцинации зрительные & Пировалерон & 2,3 & 100 \\
\hline Бред преследования, галлюцинации зрительные, страх & МДПВ & 2,3 & 100 \\
\hline Бред преследования, галлюцинации зрительные, страх & Пировалерон & 2,3 & 100 \\
\hline Бред преследования, галлюцинации зрительные, страх & МДПВ, пировалерон & 2,3 & 100 \\
\hline $\begin{array}{l}\text { Возбуждение, двигательное возбуждение, бег, защита от преследовате- } \\
\text { лей (прячется) }\end{array}$ & Пировалерон & 2,3 & 100 \\
\hline $\begin{array}{l}\text { Возбуждение, двигательное возбуждение, бег, защита от преследовате- } \\
\text { лей (прячется) }\end{array}$ & Пол мужской, пировалерон & 2,3 & 100 \\
\hline Недоброжелатели подбросят наркотики & Пировалерон & 10,0 & 91 \\
\hline Бред преследования, галлюцинации зрительные & Пировалерон & 5,0 & 91 \\
\hline Возбуждение, защита от преследователей (прячется) & Пировалерон & 4,5 & 90 \\
\hline Возбуждение, защита от преследователей (прячется) & Пол мужской, пировалерон & 4,5 & 90 \\
\hline
\end{tabular}

Т а б ли ц а 3

Зависимости между симптомами и группами принимаемых психоактивных веществ

\begin{tabular}{|c|c|c|c|}
\hline Причина & Следствие & \begin{tabular}{|c|} 
Поддержка, \\
$\%$
\end{tabular} & $\begin{array}{l}\text { Достовер- } \\
\text { ность, \% }\end{array}$ \\
\hline Суицидальные мысли & Производные пировалерона & 4,1 & 100 \\
\hline Желание спрыгнуть с высоты & Производные пировалерона & 3,6 & 100 \\
\hline Бред преследования, возбуждение, защита от преследователей (прячется) & Производные пировалерона & 2,7 & 100 \\
\hline Бред преследования, возбуждение, защита от преследователей (прячется) & $\begin{array}{l}\text { Пол мужской, производные } \\
\text { пировалерона }\end{array}$ & 2,7 & 100 \\
\hline Сенестопатия (вынимают или выпадают внутренности) & Производные пировалерона & 2,3 & 100 \\
\hline Бред преследования, возбуждение, галлюцинации зрительные & Производные пировалерона & 2,3 & 100 \\
\hline Бред преследования, галлюцинации зрительные, страх & Производные пировалерона & 2,3 & 100 \\
\hline $\begin{array}{l}\text { Возбуждение, двигательное возбуждение, бег, защита от преследовате- } \\
\text { лей (прячется) }\end{array}$ & Производные пировалерона & 2,3 & 100 \\
\hline $\begin{array}{l}\text { Возбуждение, двигательное возбуждение, бег, защита от преследовате- } \\
\text { лей (прячется) }\end{array}$ & $\begin{array}{l}\text { Пол мужской, производные } \\
\text { пировалерона }\end{array}$ & 2,3 & 100 \\
\hline Самоповреждения депрессивные & Производные пировалерона & 1,8 & 100 \\
\hline Идеи величия & Производные пировалерона & 1,8 & 100 \\
\hline Идеи отравления & Производные пировалерона & 1,8 & 100 \\
\hline Бред преследования, отсутствие одежды или раздевание & Производные пировалерона & 1,8 & 100 \\
\hline Бред преследования, отсутствие одежды или раздевание & $\begin{array}{l}\text { Пол мужской, производные } \\
\text { пировалерона }\end{array}$ & 1,8 & 100 \\
\hline Бред преследования, желание спрыгнуть с высоты & Производные пировалерона & 1,8 & 100 \\
\hline Бред преследования, нарушение сознания (дезориентировка) & Производные пировалерона & 1,8 & 100 \\
\hline Возбуждение, идеи величия & Производные пировалерона & 1,8 & 100 \\
\hline Возбуждение, суицидальные мысли & Производные пировалерона & 1,8 & 100 \\
\hline Подбросить наркотики, отсутствие одежды или раздевание & Производные пировалерона & 1,8 & 100 \\
\hline
\end{tabular}


Результаты эксперимента, представленные в таблице 2, с различной, но очень высокой степенью достоверности показывают, какие психоактивные вещества вызывают симптомы, указанные в качестве «причины» ассоциативного правила. При этом полученные АП могут быть использованы для установления возможных принятых психоактивных веществ по наблюдаемым у пациента симптомам. Причем если в «следствии» указывается связь с полом, то это мужской пол.

Результаты эксперимента, представленные в таблице 3, отражены с достоверностью $100 \%$. Параноидный синдром со зрительными галлюцинациями в сочетании с идеями реальности угрозы для жизни, с двигательным возбуждением и стра- хом оказался высокоспецифичным для приема производных пировалерона.

Также были проанализированы результаты экспериментов для психозов, развившихся на фоне употребления синтетических каннабиноидов. Оказались наиболее характерны уверенность, что врачи и недоброжелатели могут подбросить наркотики, идеи величия, а признаки, патогномоничные для приема производных пировалерона (угроза жизни, двигательное возбуждение, страх), не отражаются с соответствующей достоверностью и поддержкой. Это позволяет с вероятностью 89$90 \%$ установить этиологию психоза, вызванного употреблением вещества конкретной группы.

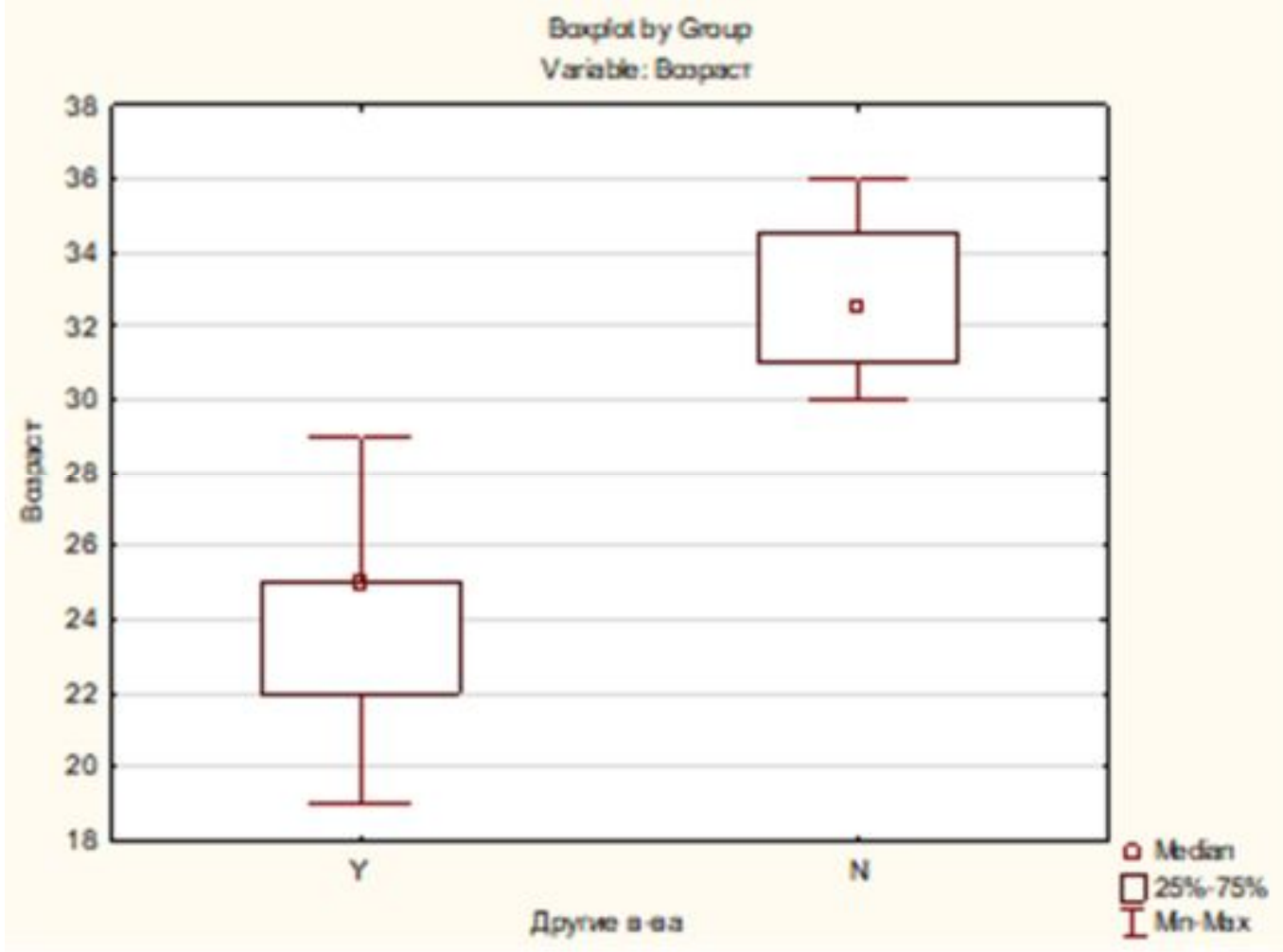

Р и с ун о к 1. Зависимость между возрастом пациента, употреблением каннабиоидов $(\mathrm{N})$ и иных психоактивных веществ (Y)

В качестве дополнительного предиктора можно использовать возрастной фактор (рис. 1). Анализ статистических данных показал, что при возрасте обследованных 32-34 года можно достоверно предполагать употребление исключительно каннабиноидов, без перехода к употреблению иных психоактивных веществ. В то время как в более раннем возрасте (22-24 года) такой переход встречается достоверно чаще.

При сочетанном употреблении производных пировалерона с синтетическими каннабиноидами, а также производных пировалерона в комбинации с синтетическими каннабиноидами и другими веществами АП показали иные результаты.
Если в клинической симптоматике психоза наблюдались проявления агрессии и отсутствие сна, то с вероятностью $100 \%$ это свидетельствует об употреблении производных пировалерона в сочетании с каннабиноидами. Если в клинической картине психоза отсутствуют боязнь того, что подбросят наркотики, идеи реальности угрозы жизни, бред преследования и стремление больного спрятаться от мнимых врагов, то с вероятностью 94\% кроме производных пировалерона и каннабиноидов больной употребляет иные психоактивные вещества. Всё это позволяет проводить диагностический поиск иных веществ, маскирующих картину психозов на фоне употребления каннабиноидов и производных пировалерона. 


\section{ВЫВОДЫ}

1. Использованный метод математического компьютерного моделирования позволяет выявить основные диагностические критерии, являющиеся значимыми для установления этиологии психоза, вызванного употреблением новых современных психоактивных веществ. Полученные ассоциативные правила в целом отвечают реальной действительности, так как показывают, какие группы психоактивных веществ в качестве «следствия» вызывают симптомы, указанные в качестве «причины» АП.

2. Для определения этиологии психоза не все симптомы оказались равнозначными. Проведенная оценка и анализ клинических проявлений с позиции АП показали, что установить пировалероновую этиологию психоза можно по характерному сочетанию симптомов: идеи реальности угрозы жизни, двигательное возбуждение, страх. Употреблению каннабиноидов достоверно соответствуют идеи величия, угрозы подброса наркотиков. Дополнительно можно учитывать возраст риска (22-24 года) перехода к употреблению иных психоактивных веществ.

3. Полученные АП могут быть использованы для установления возможных принятых препаратов по наблюдаемым симптомам. Если поиск окажется безуспешным, то это указывает либо на индивидуальные особенности пациента, либо на обнаружение ранее не встречаемого препарата.

\section{КОНФЛИКТ ИНТЕРЕСОВ}

Авторы заявляют об отсутствии конфликта интересов в связи с публикацией данной статьи.

\section{ИСТОЧНИК ФИНАНСИРОВАНИЯ}

Авторы заявляют об отсутствии финансирования при проведении исследования.

\section{СООТВЕТСТВИЕ ПРИНЦИПАМ ЭТИКИ}

Работа соответствует этическим стандартам, разработанным в соответствии с Хельсинской декларацией ВМА (протокол заседания этического комитета ФГБОУ ВО «Красноярский государственный медицинский университет имени проф. В.Ф. Войно-Ясенецкого» Минздрава России № 76/2016 от 4 мая 2017 г.).

\section{ЛИТЕРАТУРА}

1. Анцыборов А.В., Мрыхин В.В. Синтетические каннабиноиды: новая матрица аддикции. Интерактивная наука. 2017. 4 (14): 25-38.

2. Бохан Н.А., Мандель А.И., Артемьев И.А., Ветлугина Т.П., Солонский А.В., Прокопьева В.Д., Иванова С.А., Невидимова Т.И. Эпидемиология, клинико-патобиологические закономерности и профилактика психических и поведенческих расстройств в результате злоупотребления психоактивными веществами (региональный аспект). Сибирский вестник психиатрии и наркологии. 2006; 3 (42): 25-32.

3. Гуреева Д.А., Гуреев Г.А., Уваров И.А., Лекомцев В.Т. Особенности дифференциальной диагностики шизофрении, интоксикационных психозов вследствие употребления синтетических каннабиноидов и органических психо- зов на современном этапе. Практическая медициина. 2017; 2: 19-22.

4. Иванова Л.А., Терских Т.В., Тарасенко Т.В., Иванова Л.В. Психотические расстройства у лиц, употребляющих синтетические каннабиноиды (спайсы). Бюллетень Восточно-Сибирского научного иентра СО РАМН. 2017; 2. 2 (114): 14-17.

5. Каркищенко Н.Н. Концептуальное пространство и топологические структуры биомедицины. Биомедицина. 2005. 1: 5- 16.

6. Каркищенко Н.Н. Основы биомоделирования. М.: Межакадемическое издательство, ВПК, 2005: 608.

7. Ларченко А.В., Суворов М.А., Андрюхин В.И., Кауров В.И., Суворов А.В. Синтетические катиноны и каннабиноиды - новые психоактивные вещества (обзор). Современные технологии в медицине. 2017; 9, 1: 185-197.

8. Мезенцева Л.В., Перцов С.С. Математическое моделирование в биомедицине. Вестник новых медицинских технологий. 2013; ХХ, 1: 11.

9. Менделевич В.Д. Психотические расстройства в результате употребления наркотиков: современное состояние проблемы. Наркология. 2014. 7: 93-100.

10. Мрыхин В.В., Анцыборов А.В. Психиатрические аспекты употребления дизайнерских наркотиков и новых психоактивных веществ. Интерактивная наука. 2017. 12: 64-74.

11. Пичугина Ю.А., Березовская М.А., Коробицина Т.В. Анализ современной ситуации употребления психоактивных веществ. Сибирское медицинское обозрение. 2016; 1: 4047.

12. Семке В.Я., Бохан Н.А. Транскультуральная аддиктология. Томск : Изд-во Том. ун-та, 2008: 588.

13. Соседова Л.М., Филиппова Т.М. Роль биомоделирования в системе химической безопасности человека. Экология человека. 2017. 7: 46-52.

14. Хорошилов Г.П., Худяков А.В. Интоксикационные психозы, связанные с употреблением современных психоактивных веществ. Практическая медицина. 2015; 5 (90): 7-10.

15. Шарова Е.Н., Злоказова М.В. Феноменологические особенности психических расстройств от современных «дизайнерских» наркотиков. Практическая медицина. 2017; 2 (102): 23-25.

16. Hurst D. Psychosis Associated With Synthetic Cannabinoid Agonists: A Case Series. American Journal of Psychiatry. 2011. 168: 1119-1119.

17. Hipp J., Guntzer U., Nakaeizadeh G. Algorithms for Association Rule Mining - A General Survey and Comparison. In Proc. ACM SIGKDD International Conference on Knowledge Discovery and Data Mining, 2000.

18. Agrawal R., Srikant R. Fast Discovery of Association Rules. In Proc. of the 20th International Conference on VLDB, Santiago, Chile, September 1994.

19. Every-Palmer S. Synthetic cannabinoid JWH-018 and psychosis: an explorative study. Drug and Alcohol Dependence. 2011; 117: 152-157.

20. Thornton S.L. Lo J., Clark R.F., Wu A.H.B., Gerona R.R. Simultaneous detection of multiple designer drugs in serum, urine, and CSF in a patient with prolonged psychosis. Clin Toxicol (Phila). 2012. 10: 1165-1168.

21. Van der Veer N., Friday J. Persistent psychosis following the use of Spice. Schizophr. Res. 2011; 130 (1-3): 285-286.

22. Черепкова Е.В., Гуревич К.Г., Счастный Е.Д., Антонов А.Р. Общая характеристика наркотиков-аналогов и их составляющих: курительные смеси «спайс», энтеогены. Системный анализ и управление в биомедицинских системах. 2012. 11; 3: 685-688.

Поступила в редакцию 1.06.2018 Утверждена к печати 6.11.2018 
Афанасьева Наталья Анатольевна, ассистент кафедры психиатрии и наркологии с курсом последипломного образования Березовская Марина Альбертовна, д.м.н., доцент, заведующая кафедрой психиатрии и наркологии с курсом последипломного образования. Коробицина Татьяна Валерьевна, д.м.н., профессор кафедры психиатрии и наркологии с курсом последипломного образования. Пичугина Юлия Анатольевна, к.м.н., доцент кафедры психиатрии и наркологии с курсом последипломного образования. Арапиев Юрий Уматович, к.м.н., доцент кафедры психиатрии и наркологии с курсом последипломного образования. Виноградов Константин Анатольевич, д.м.н., профессор, заведующий кафедрой медицинской кибернетики и информатики Быкова Валентина Владимировна, д.физ-мат.н., профессор кафедры высшей и прикладной математики Института математики и фундаментальной информатики.

Катаева Алина Владимировна, аспирант кафедры высшей и прикладной математики Института математики и фундаментальной информатики.

Березовская Марина Альбертовна, mberezovska@mail.ru

Афанасьева Наталья Анатольевна, afanaseva76@yahoo.com

УДК 616.89-008.481:614.283:178.8:303.725.23

For citation: Afanasyeva N.A., Berezovskaya M.A., Korobitsina T.V., Pichugina Yu.A., Arepyev Yu.A., Vinogradov K.A., Bykova V.V., Kataeva A.V. Experience in use of the method of mathematical modeling of mental disorders in the combined use of modern synthetic psychoactive substances. Siberian Herald of Psychiatry and Addiction Psychiatry. 2018; 4 (101): 28-34. https://doi.org/10.26617/1810-3111-2018-4(101)-28-34

\title{
Experience in use of the method of mathematical modeling of mental disorders in the combined use of modern synthetic psychoactive substances
}

\section{Afanasyeva N.A. ${ }^{1}$, Berezovskaya M.A. ${ }^{1}$, Korobitsina T.V. ${ }^{1,}$, Pichugina Yu.A. ${ }^{1}$, Arepyev Yu.A. ${ }^{1}$, Vinogradov K.A. ${ }^{1}$, Bykova V.V. ${ }^{2}$, Kataeva A.V. ${ }^{2}$}

\author{
${ }^{1}$ Krasnoyarsk State Medical University named after Professor V.F. Voyno-Yasenetsky \\ Partizan Zheleznyak Street 1, 660022, Krasnoyarsk, Russian Federation \\ ${ }^{2}$ Siberian Federal University \\ Svobodny Avenue, 79, 660041, Krasnoyarsk, Russian Federation.
}

\section{ABSTRACT}

Objective was to analyze the possibility of creating a mathematical computer model for the diagnosis of mental disorders due to the use of modern synthetic psychoactive substances. Despite the similarity of the clinical picture of psychotic disorders due to the use of modern synthetic psychostimulants and cannabinoids, it was possible to identify differential diagnostic criteria of psychoses, cause-effect relationships that were of great importance in the treatment of disorders due to the use of synthetic psychoactive substances.

\section{Keywords: mathematical modeling, associative rules, psychoactive substances, schizophrenia-like mental disorders.}

\section{REFERENCES}

1. Antsyborov A.V., Mrykhin V.V. Sinteticheskie kannabinoidy: novaya matrica addikcii [Synthetic cannabinoids: new matrix addiction] Interaktivnaya nauka - Interactive Science. 2017. 4 (14): 25-38 (in Russian).

2. Bokhan N.A., Mandel A.I., Artemyev I.A., Vetlugina T.P Solonsky A.V., Prokopyeva V. D., Ivanova S.A., Nevidimova T.I. Epidemiologiya, kliniko-patobiologicheskie zakonomernosti i profilaktika psikhicheskikh i povedencheskikh rasstroystv $v$ rezul'tate zloupotrebleniya psikhoaktivnymi veshchestvami (regional'nyy aspekt) [Epidemiology, pathobiological regulatrities of prevention of mental and behavioral disorders as a result of substance abuse (regional aspect)]. Sibirskii vestnik psikhiatrii i narkologii - Siberian Herald of Psychiatry and Addiction Psychiatry. 2006; 3 (42): 25-32 (in Russian).

3. Gureeva D.A., Gureev G.A., Uvarov I.A., Lekomcev V.T. Osobennosti differencial'noj diagnostiki shizofrenii, intoksikacionnyh psihozov vsledstvie upotrebleniya sinteticheskih kannabinoidov i organicheskih psihozov na sovremennom ehtape [Features of differential diagnosis of schizophrenia toxic psychoses as a result of the use of synthetic cannabinoids and organic psychoses at the present stage]. Prakticheskaya medicina - Practical Medicine. 2017; 2: 19-22 (in Russian).

4. Ivanova L.A., Terskih T.V., Tarasenko T.V., Ivanova L.V. Psihoticheskie rasstrojstva u lic, upotreblyayushchih sinteticheskie kannabinoidy (spajsy) [Psychotic disorders in people using synthetic cannabinoids (spice)]. Byulleten' VostoshnoSibirskogo nautsnogo tcentra SO RAMN - Bulletin of EastSiberian Scientific Center SB RAMS. 2017; 2, 2 (114): 14-17 (in Russian).
5. Karkishchenko N.N. Konceptual'noe prostranstvo i topologicheskie struktury biomediciny [Conceptual space and typological structures of biomedicine]. Biomedicina - Biomedicine. 2005. 1: 5-16 (in Russian).

6. Karkishchenko N.N. Osnovy biomodelirovaniya [Bases of biomodelling]. Moscow: Mezhakademicheskoe izdatel'stvo, VPK, 2005: 608 (in Russian).

7. Larchenko A.V., Suvorov M.A., Andryukhin V.I., Kaurov V.I., Suvorov A.V. Sinteticheskie katinony i kannabinoidy novye psihoaktivnye veshchestva (obzor) [Synthetic cathinones and cannabinoids are new psychoactive substances (review)]. Sovremennye tekhnologii v medicine - Modern Technologies in Medicine. 2017; 9 (1): 185-197 (in Russian).

8. Mezentseva L.V., Pertsov S.S. Matematicheskoe modelirovanie $\mathrm{v}$ biomedicine [Mathematical modeling in biomedicine]. Vestnik novyh medicinskih tekhnologij-Bulletin of New Medical Technologies. 2013. XX (1): 11 (in Russian).

9. Mendelevich V.D. Psihoticheskie rasstrojstva v rezul'tate upotrebleniya narkotikov: sovremennoe sostoyanie problemy [Psychotic disorders due to drug use: current state of the problem]. Narkologiya -- Narcology. 2014; 7: 93-100 (in Russian).

10. Mrykhin V.V., Antsyborov A.V. Psihiatricheskie aspekty upotrebleniya dizajnerskih narkotikov i novyh psihoaktivnyh veshchestv [Psychiatric aspects of use of designer drugs and new psychoactive substances]. Interaktivnaya nauka - Interactive Science. 2017; 12: 64-74 (in Russian).

11. Pichugina Yu.A., Berezovskaya M.A., Korobicina T.V. Analiz sovremennoj situacii upotrebleniya psihoaktivnyh veshchestv [Analysis of current situation of psychoactive substance use]. 
Sibirskoe medicinskoe obozrenie - Siberian Medical Review. 2016; 1: 40-47 (in Russian).

12. Semke V.Ya., Bokhan N.A. Transkul'tural'naya addiktologiya [Transcultural addictology]. Tomsk: Publishing House of Tomsk University, 2008: 588 (in Russian).

13. Sosedova L.M., Filippova T.M. Rol' biomodelirovaniya v sisteme himicheskoj bezopasnosti cheloveka [The role of biosimulation in human chemical safety system]. Ekologiya cheloveka - Human Ecology. 2017; 7: 46-52 (in Russian).

14. Horoshilov G.P., Hudyakov A.V. Intoksikacionnye psihozy, svyazannye $\mathrm{s}$ upotrebleniem sovremennyh psihoaktivnyh veshchestv [Induced psychotic disorders associated with modern psychoactive substances usage]. Prakticheskaya medicina - Practical Medicine. 2015; 5 (90): 7-10 (in Russian).

15. Sharova E.N., Zlokazova M.V. Fenomenologicheskie osobennosti psihicheskih rasstrojstv ot sovremennyh «dizajnerskih» narkotikov [Phenomenological peculiarities of psychic disorders caused by modern "designer" drugs]. Prakticheskaya me dicina - Practical Medicine. 2017; 2 (102): 23-25 (in Russian).

16. Hurst D. Psychosis Associated With Synthetic Cannabinoid Agonists: A Case Series. American Journal of Psychiatry. 2011. 168: 1119-1119.

17. Hipp J., Guntzer U., Nakaeizadeh G. Algorithms for Association Rule Mining - A General Survey and Comparison. In
Proc. ACM SIGKDD International Conference on Knowledge Discovery and Data Mining, 2000.

18. Agrawal R., Srikant R. Fast Discovery of Association Rules. In Proc. of the 20th International Conference on VLDB, Santiago, Chile, September 1994.

19. Every-Palmer S. Synthetic cannabinoid JWH-018 and psychosis: an explorative study. Drug and Alcohol Dependence. 2011. 117: 152-157.

20. Thornton S.L. Lo J., Clark R.F., Wu A.H.B., Gerona R.R. Simultaneous detection of multiple designer drugs in serum, urine, and CSF in a patient with prolonged psychosis. Clin Toxicol (Phila). 2012. 10: 1165-1168.

21. Van der Veer N., Friday J. Persistent psychosis following the use of Spice. Schizophr. Res. 2011; 130 (1-3): 285-286.

22. Cherepkova E.V., Gurevich K.G., Schastnyj E.D., Antonov A.R. Obshchaya harakteristika narkotikov-analogov i ih sostavlyayushchih: kuritel'nye smesi «spajs», ehnteogeny [General characteristics of designer drugs and their components: the smoking blends "spice", the entheogens]. Sistemnyj analiz $i$ upravlenie $v$ biomedicinskih sistemah - System analysis and management in biomedical systems. 2012. 11; 3: 685688 (in Russian)

Received June 1.2018 Accepted November 6.2018

Afanasyeva Natalya A., assistant at the Department of Psychiatry and Narcology with a course of postdegree education, Krasnoyarsk State Medical University named after Professor V.F. Voyno-Yasenetsky, Krasnoyarsk, Russian Federation.

Berezovskaya Marina A., MD, associate professor, Head of the Department of Psychiatry and Narcology with a course of postdegree education, Krasnoyarsk State Medical University named after Professor V.F. Voyno-Yasenetsky, Krasnoyarsk, Russian Federation.

Korobitsina Tatyana V., MD, professor of the Department of Psychiatry and Narcology with a course of postdegree education, Krasnoyarsk State Medical University named after Professor V.F. Voyno-Yasenetsky, Krasnoyarsk, Russian Federation; Siberian Federal University, Krasnoyarsk, Russian Federation.

Pichugina Yulia A., PhD, associate professor at the Department of Psychiatry and Narcology with a course of postdegree education, Krasnoyarsk State Medical University named after Professor V.F. Voyno-Yasenetsky, Krasnoyarsk, Russian Federation.

Arepyev Yury U., PhD, associate professor at the Department of Psychiatry and Narcology with a course of postdegree education, Krasnoyarsk State Medical University named after Professor V.F. Voyno-Yasenetsky, Krasnoyarsk, Russian Federation.

Vinogradov Konstantin A., MD, Prof., Head of the Department of Medical Cybernetics and Information Science, Krasnoyarsk State Medical University named after Professor V.F. Voyno-Yasenetsky, Krasnoyarsk, Russian Federation.

Bykova Valentina V., doctor of physical and mathematical sciences, professor of the Department of the Higher and Applied Mathematics of Institute of Mathematics and Fundamental Information Science, Siberian Federal University, Krasnoyarsk, Russian Federation.

Katayeva Alina V., graduate student of the Department of the Higher and Applied Mathematics of Institute of Mathematics and Fundamental Information Science, Siberian Federal University, Krasnoyarsk, Russian Federation.

Berezovskaya Marina A., mberezovska@mail.ru

Afanasyeva Natalya A., afanaseva76@yahoo.com 